\title{
Geosciencees
}

http://dx.doi.org/10.1590/0370-44672018720110

Yawar Hussain ${ }^{1,8}$

https://orcid.org/0000-0002-4155-6764

Sehar M. Hussain ${ }^{2,9}$

https://orcid.org/0000-0003-2846-0327

Salvatore Martino ${ }^{3,10}$

https://orcid.org/0000-0003-1277-7784

Martin Cardenas-Soto ${ }^{4,11}$

https://orcid.org/0000-0002-6586-469X

Omar Hamza ${ }^{5,12}$

https://orcid.org/0000-0002-5048-0423

Juan F. Rodriguez-Rebolledo ${ }^{1,13}$

https://orcid.org/0000-0003-2929-7381

Rogério Uagoda ${ }^{6,14}$

https://orcid.org/0000-0002-9448-1313

Hernan Martinez-Carvajal7,15

https://orcid.org/0000-0001-7966-1466

'Universidade de Brasília UnB, Departamento de Engenharia Civil e Ambiental, Brasília - Distrito Federal - Brasil.

${ }^{2}$ University of Gujrat, Department of Chemical Engineering, Gujrat - Punjab - Pakistan.

3"Sapienza" Università di Roma, Dipartimento di Scienze della Terra, Rome - Italia.

${ }^{4}$ Universidad Nacional Autónoma de México | UNAM, Facultad de Ingeniería, México City - México

5University of Derby, College of Engineering and Technology, Mechanical Engineering and the Built Environment, Derby - United Kingdom of Great Britain and Northern Ireland.

'Universidade de Brasília - UnB, Departmento de Geografia, Brasília - Distrito Federal - Brasil.

7Universidad Nacional de Colombia: Medellín Facultad de Minas, Medellín - Colombia.

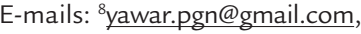

'seharmuzaffarhussain@gmail.com,

${ }^{10}$ salvatore.martino@uniroma1.it, ${ }^{11}$ martinc@unam.mx, 120.Hamza@derby.ac.uk, ${ }^{13}$ jrodriguezr72@hotmail.com

${ }^{14}$ rogeriouagoda@unb.br, ${ }^{15}$ hmartinezc30@gmail.com

\section{Typological analysis of slidequakes emitted from landslides: experiments on an expander body pile and Sobradinho landslide (Brasilia, Brazil)}

\begin{abstract}
Reactivation of a landslide is usually accompanied by microseismic signals emitted from the deforming soil mass. The reproduction of similar signals in a physical model test conducted under control conditions can allow researchers to explore and test such complicated signals to improve the prediction of full-scale failure. The present study investigates the similarity between the slidequakes (microseismicity) naturally emitted from an existing colluvial landslide (Sobradinho, Brazil) in response to rainfalls and the emissions generated by a pullout test of an expander body (EB) pile in tropical soil under controlled conditions. The microseismic signals emitted from both experimental sites (i.e. the landslide and the EB pile test) were recorded and compared. Data were acquired by mini-arrays of four short-period seismometers. For the signal nomenclature, a typological scheme was adopted, in which sonograms/spectral contents of the signals were used. As a result, short duration microseismic signals were observed during the pullout test. In contrast, at the Sobradinho landslide, the testing detected signals of different characteristics whose source mechanisms have remained ambiguous, mainly because of the short duration of the data campaigns. However, at the landslide, propagating events were observed that might be attributed to the energies generated by the river bedload during the heavy rains. The present study offers some insight into the pre-collapse dynamic behavior of unstable slopes in clayey formations.
\end{abstract}

Keywords: expander body pile; extraction test; sonograms; spectral analysis; tropical clay. 


\section{Introduction}

Reactivation of landslide associated with rainfall is a common phenomenon in colluvial soils where these deposits are involved in rupture and sliding. This phenomenon is accompanied by microseismic activities, which can be recorded by sensors and used for the analysis of landslide deformation and, hence, strengthening the landslide's early warning system (Vouillamoz et al., 2018). Same is the case with the colluvial slopes in Brazil, where slope failures are triggered by heavy summer rainfalls, usually from December to March. These slopes are characterized by relatively shallow failure surface depths with dependent variations of the saturated hydraulic conductivity that lead to pore pressure build up (Martins et al., 2017).

The fluctuations in groundwater level and pore-pressure are common landslide triggers because this can change the effective stresses, alter the shear strength in the soil (Hamza and Bellis, 2008) and ultimately disturb the equilibrium condition, leading to material deformation and consequently the microseismic energy release in response to the sediment's deformations (Walter and Joswig, 2009). These microseismic signals having magnitudes $M_{L}<0$ for local magnitude $\left(M_{L}\right)$ scale can be

\section{Material and methods}

\subsection{Prototype experiment}

A methodology for simulating landslide seismic signals emitted in the proximity of a tropical soil at field-scale was developed. Initially, two options were considered as potential ways to induce failure in the soil. The first was to induce a slope failure by increasing the degree of saturation of the soil. However, this option was unfavorable because of two main problems related to the highly porous tropical clay dominating the surficial geology of the site. First, based on preliminary numerical computations carried out by the University of Brasilia on this type of soil, a significant amount of water would be necessary to change the saturation degree of the soil. Due to the high porosity of the soil (>55\%), water would run through the soil mass to lower elevations saturating them utilized for a proper understanding of material instabilities and how they can evolve into major hazardous phenomena (Planès et al., 2016).

The changes of rainfall-induced effective stress are accumulated in the soil and compensated by sliding that releases microseismic vibrations. In this way, the sliding can be resolved into several occurrences of propagation of sliding plane or soil failure. This mechanism is assumed to be similarly created in a pullout experiment as described in section 2.1. However, it differs in the type and level of the applied stresses which are very low in the case of landslide under the influence of triggering factors (e.g. rainfall).

However, the associated microseismic emissions from landslides are confusing because of the involvement of two sources: (i) endogenic - from deep within the landslide because of material deformation, and (ii) exogenic - from surficial processing such as rockfall and movement of debris (Vouillamoz et al., 2018). The separation of these two source mechanisms is of prime importance in any microseismic based landslide hazard assessment study. The presence of endogenous microseismicity is evident from many past studies (Gomberg et al., 1995; Walter et al., 2012;
Tonnellier et al., 2013; Provost et al., 2017; Fiorucci et al., 2017; Vouillamoz et al., 2018).

In the present study, landslide microseismic signals were generated on a field scale experiment using an expander body (EB) pile. The experiment was performed under controlled conditions in the experimental field of the University of Brasilia, Brazil. This is the first time that seismic signals due to shear zones in the soil have been simulated under controlled conditions. The goal was to analyze the microseismic signals emitted from a propagating soil failure as a consequence of the pullout load applied on the EB pile. In the second round, the experiments were performed on Sobradinho landslide for the analysis of its seasonal dynamics in terms of microseismic emissions. An attempt was carried out to recognize a similar source mechanism between the EB pile and natural-scale landslide in terms of the released microseismic signals. The spectral anomalies observed over supersonograms were used in the typological classification of the signals released in response to the pullout test on an EB pile and by the seasonal dynamics at the natural scale of the Sobradinho landslide. In both experiments the same event screening was used. first (Silva, 2009). Second, due to the high porosity, this water would also flow in all directions, which must be avoided because of the proximity of a large building.

The second option was to induce failure in the EB pile. EB pile technology has been used successfully to increase the pile toe capacity in loose to dense soils (Arce and Herrera, 2016). However, in the present study, a pullout test on an EB pile is used as a mechanism that leads to soil failure. This would affect only the soil at the location of the experiment and not the wider surrounding area. During the extraction process, the shear plane propagation is supposed to evolve in the soil. In the present study this methodology is followed because of three main advantages: (i) the ability to control landslide exogenic pro- cesses allowing the record of seismic signature of soil failure, (ii) low cost in terms of both time and resources, and (iii) the non-destructive nature of the test.

The experimental site was chosen to be in the city of Brasilia (Brazil) in tropical clay. The pullout test took place on Wednesday (21/02/2018) between 10:00-14:00h. Two concrete blocks were chosen and above these blocks, two steel rods were placed. A load cell was positioned above the rods and a hydraulic jack was attached to this load cell. This formed the base for applying a pulling out force on the EB pile by a manually operated oil pump. Attached to the hydraulic jack there were two smaller metallic rods on which four extensometers were installed for monitoring the vertical displacement of the pile. This set up 
allowed to control the exogenous processes and record the failure mechanics of the soil. In this way, all microseismic energies were produced by endogenic processes throughout the experiment.

The region of Brasilia is covered by a mantle of Tertiary-Quaternary age detritus-lateritic soil composed mainly of red-yellow Latosols, according to the Brazilian soil classification system. The thickness of this cover is relatively depending on the topography, vegetation and rock of origin and can range from centimeters to tens of meters. The high degrees of weathering and leaching have been responsible for the formation of this soil, which led to the development of a very porous, metastable aggregate structure with a large proportion of voids and, consequently, low density. Therefore, this soil is known as "porous clay"

Figure 1

Prototype experiment (a) White window location of Brasilia (red rectangle) on a Brazilian map and the location of test site (black rectangle) in Brasilia, (b) Schematic of the EB pile load test, (c) mini-array configuration (d) its blind zone (e) experimental set up used for the pullout test on EB pile and $(f)$ is the soil profile of the experimental site. by local geotechnical engineers. Due to its aggregate state and metastable structure, this clay has a low penetration resistance standard (Standard Penetration Test SPT-N from 1 to 6 strokes; stable meta structure) and high permeability (from $10^{-3}$ to $10^{-4}$ $\mathrm{m} / \mathrm{s}$; particles in an aggregate state), similar to that of fine granular soils, which, incidentally, is how its texture is presented in its natural state. Due to its high porosity and cementitious bond type, it has a highly unstable structure when subjected to increased moisture and/or changes in the state of stresses, almost always presenting a volume variation as high as the variation of these factors (referred to as a collapsed structure. A soil profile of the experimental field is shown in Figure 1f.

The seismic acquisition system consisted of four short-period $(2 \mathrm{~Hz})$ seismometers, REFTEK-130 dataloggers and GPS locks, deployed in the form of a mini-array of the specified array of four sensors - commonly referred to as seismic navigation system (SNS) (Joswig, 2008) as explained in section 2.3.1. The mini-array used for the monitoring of EB pile had an aperture (distance between central and satellite sensors) of 10 meters (Figure 1). It was deployed by using three nails at angles, which were measured using a magnetic compass. The same mechanism of mini-array installation was adopted for the experiments at a natural scale. Because the target signals are characterized by the high-frequency contents, the choice of the sensors is usually of short period seismometers together with a high sampling rate and continuous data recording instruments (Hussain et al., 2017).

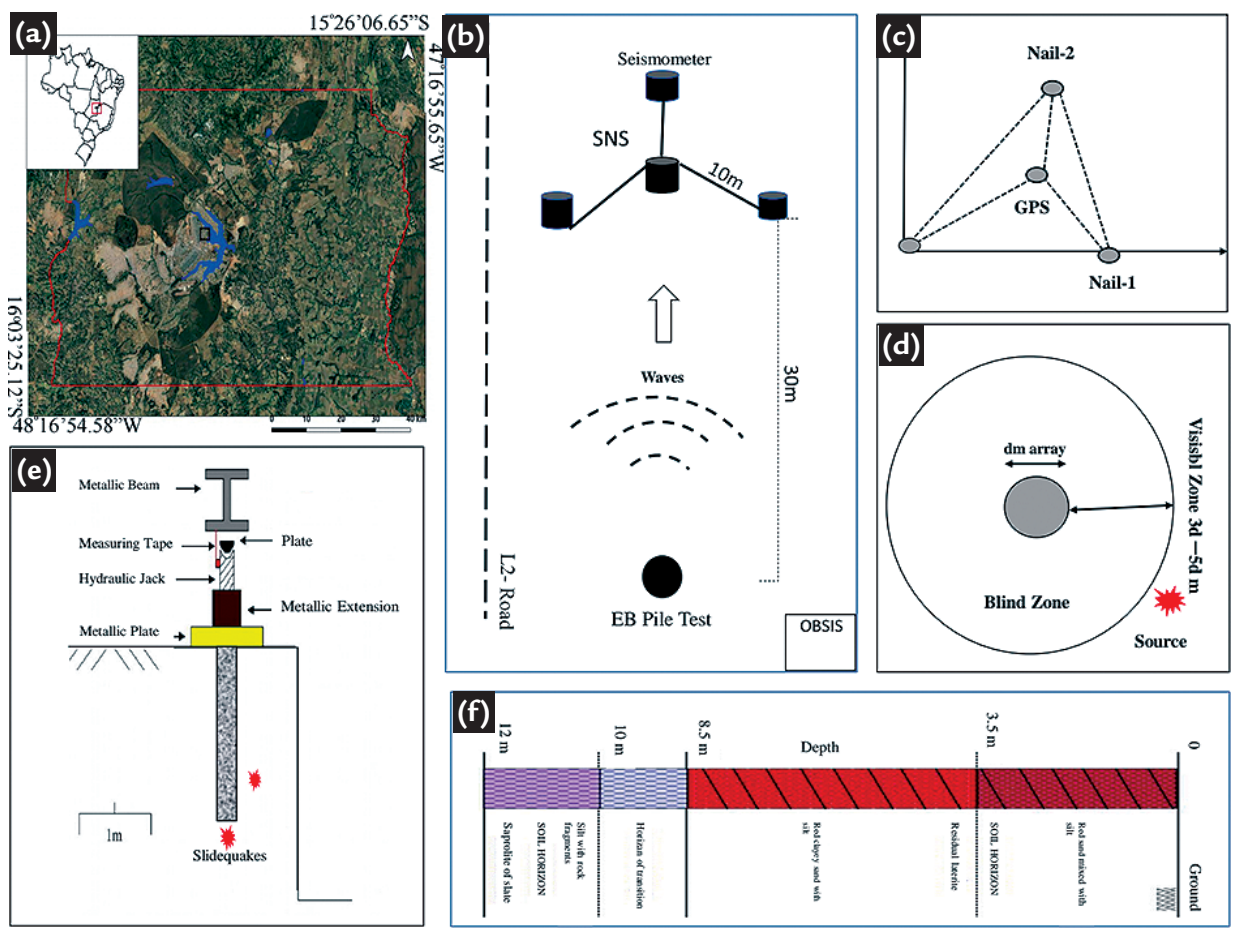

\subsection{Natural scale experiment (landslide)}

The slope selected for this study is located within the Federal District of Brazil near a cow and horse farm in the vicinity of 'Rua do Matto'. This landslide is an E-W trending rotational slip surface. The landslide extends over an area of approximately $150 \mathrm{~m}$ long and $70 \mathrm{~m}$ wide. The landslide is a result of gravity-induced instability caused by the river cutting at the bottom of the slope. The alluvial plain, fan and colluvial deposits are the geomorpho- logical features in the surrounding area of the landslide (Braga et al., 2018). Geologically, the area is composed of carbonate rocks of Paranoá group of Quaternary age.

Seismic data were acquired for a duration of 10-days by deploying two SNS at the Sobradinho landslide (Figure 2). The first mini-array (SNS-1) has an aperture of 15 meters, while the second array (SNS-2) is of about 25 meters in aperture. The layout of the two SNS seismic covers most of the landslide with particular concentration on the lower part of the slope which was expected to show the highest dynamic activities in terms of soil movement (toe erosion).

The data were recorded at a sampling rate of 1000 sample/second at the prototype field experiment and 250 sample/second for the natural scale experiment. In both experiments (EB pile and Sobradinho landslide), the recording system remained the same. 


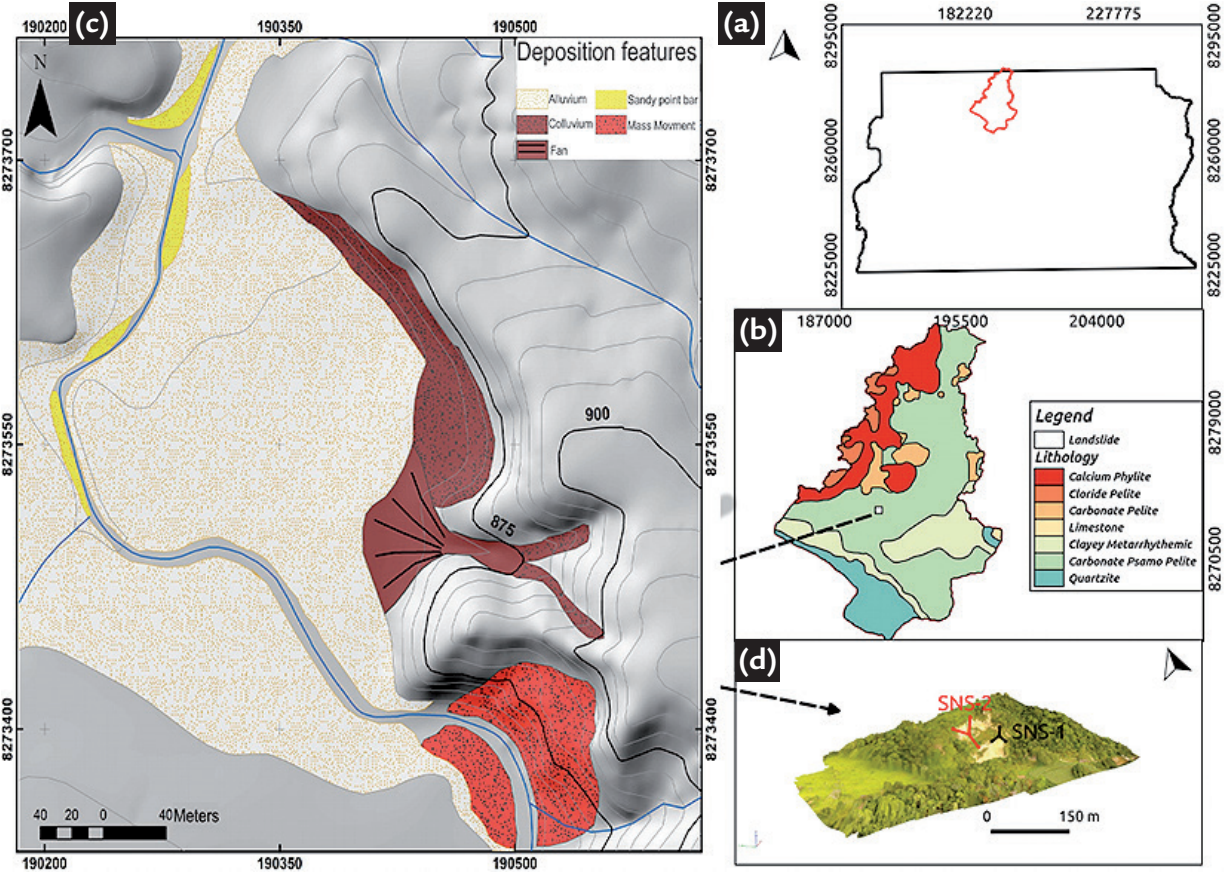

\subsection{Nanoseismic monitoring}

Nanoseismic Monitoring (NM) is a passive seismic technique and it involves specialized acquisition and processing methods for the detection and localization of weak energy signals having a local magnitude of $M_{L}<0$, usually

less than the background noise levels (Walter et al., 2011). The acquisition is performed by the specialized array of sensors (SNS) while processing is done in a dedicated software NanoseismicSuit (www.nanoseismic.net). The
Figure 2

(a) Administrative boundary of Brasilia and position of Contagem River basin on the map of Brasilia. (b) The litho-technical units of the Contagem River basin and the white rectangle is the position of the study area (c) Geomorphological features of the area such as alluvium, colluvium and sand bars (Adopted from Braga et al. 2018) (d) Positions of mini-arrays in an orthomosaic photo of the landslide.

software has two basic modules, one is SonoView used for the weak energy event screening from the noisy environment. The second module is Hypoline which is used for the detection of these weak energy events.

(Joswig, 2008; Hussain et al., 2019). The aperture size is a function of slant distance (source-receiver distance) which depends on the study objectives (Joswig, 2008). The aperture is a very crucial component of this system because it resolves only those events that lie within this array aperture (central-satellite station distance).

their high energy counterpart. Thus, the knowledge of the characteristic spectral contents of noise or events of interest helps in the identification of microseismic events. Resistant statistics is utilized in order to minimize the impacts of outliers (noise events) in the correct identification of weak events (Sick et al., 2014). Supersonogram is a combined presentation of vertical component sonograms of all four stations of one SNS. So, one pixel of supersonogram is a stack of four vertical component sonograms. In this way, a large amount of data can be visualized on short computer screen.

and $\mathrm{S}$ wave arrivals that made their phase picking difficult. In these scenarios, simple and fast spectral analyses of the microseis- 
mic signals became an attractive choice.

The common typologies of the microseismic signals detected in the past studies using spectral analysis are of quake, tremor, impulsive and harmonic. Tremors are characterized as being of medium duration, emergent onset, multiple events, and having a dominant frequency up to $50 \mathrm{~Hz}$. Dispersive signals are of long duration, emergent onset, single event, and have a dominant frequency up to $150 \mathrm{~Hz}$. Impulsive signals are of high-frequency onset and are of short duration. Their source mechanisms in the case of clayey landslides are fluid transfer and transient slip events (Gomberg et al., 2011). Harmonic signals have various attenuation patterns, single magnitude and long duration (Vouillamoz et al., 2018). Some of the signal typologies recorded in the previous studies are shown in Figure 3.
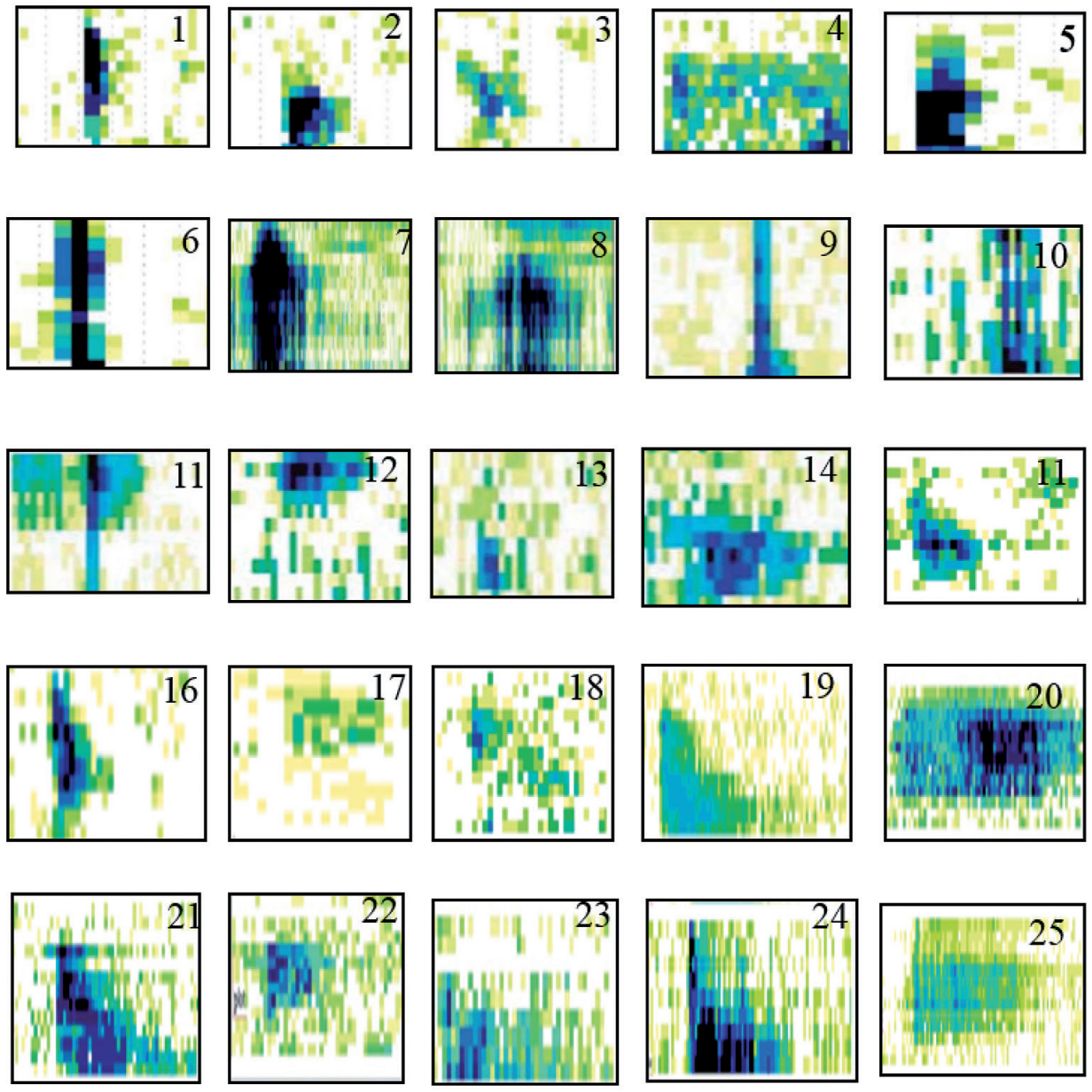

based on supersonogram screening derived from the previous studies. First four rows (1 to 20) present the landslide microseismicity recorded after the rainy events modified from Vouillamoz et al., 2018 and Walter et al., 2011; 2012; 2013). Next row (21 to 25 presents the microseismic events observed over an active fault (Häge and Joswig, 2009). The supersonogram patterns of the external factors are shown in the last row as human footsteps (28), helicopter noise (29), environmental noise $(20,31)$ (Vouillamoz et al., 2018). Y-axis is the log of frequency and axis is the time in seconds. Color bar presents energy, and increases from light to dark color.
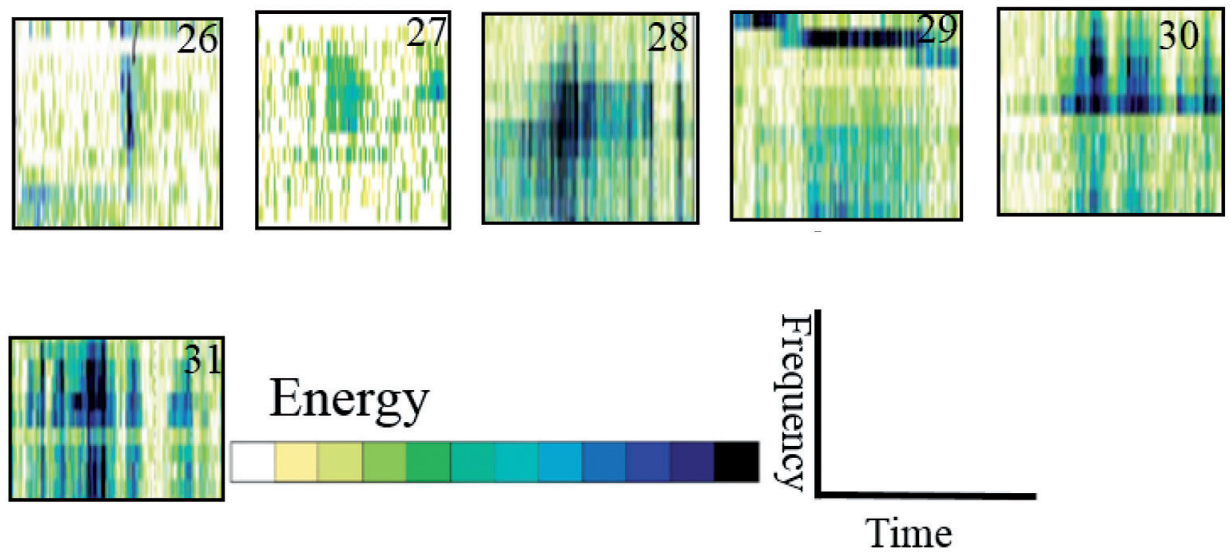

\section{Results and discussion}

In response to the application of pullout force on the EB pile, an increase in soil displacement was observed. This displacement is the result of soil failure along the developed shear zones surrounding the pile. The

shear zones might have propagated joining the adjacent microfractures as usually occur in the case of activation or reactivation of landslides. These propagating shear zones released energies which were recorded by the surface sensors (seismometers). The broad band spiky tremors with clear onsets were observed at the middle of pull out test, the emergence rate of which increased at the end of the experiment (Figure 4). 


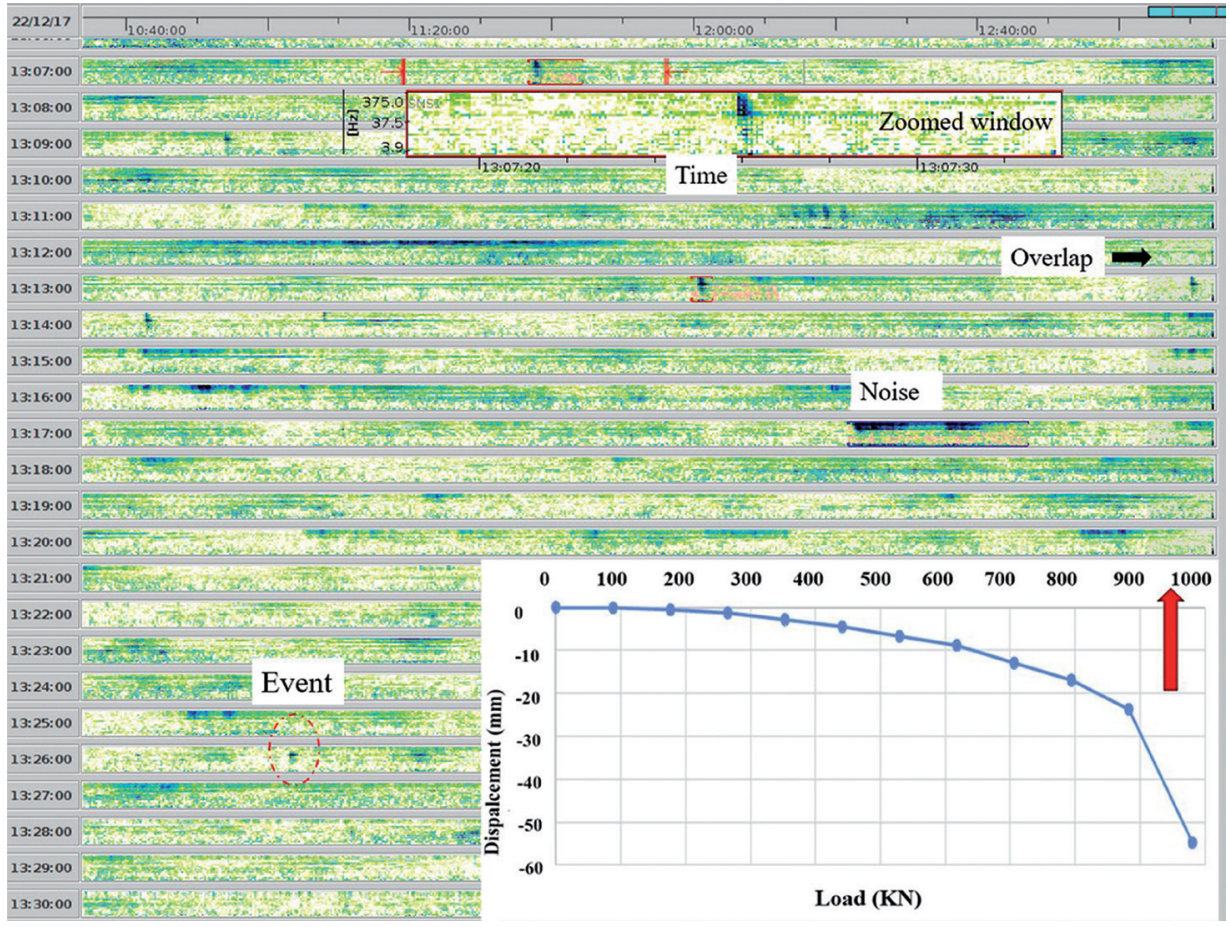

The emergence of similar signals was expected in the landslide testing because of the rainfall-induced pore pressure along the existing slip surface that can lead to the expected generation of microseismic events. To this end, the seismic records of dry (no stress alteration) and immediately after rainfall (with alteration of effective stress) events were analyzed in order to understand their typologies. The supersonogram patterns of the dry period do not show any event that can be used for typological analysis. This can be linked to the absence of dynamic activity at the site. From the records of saturated conditions (during and after rainfall), there are many events observed on the supersonograms (1 to 11 in Figure 5). The signals observed after rainfall have shown various typologies as high frequency and short duration spiky (4 and 6 in Figure 5), or high frequency and long duration (8 to 10 in Figure 5).

Another interesting type of signals was observed during the rainy season. These signals were of propagating type and were observed only during the record of rainy days when the river discharge was high (3 in Figure 5). This may suggest these signals are possibly associated with the bedload of the Contagem River.
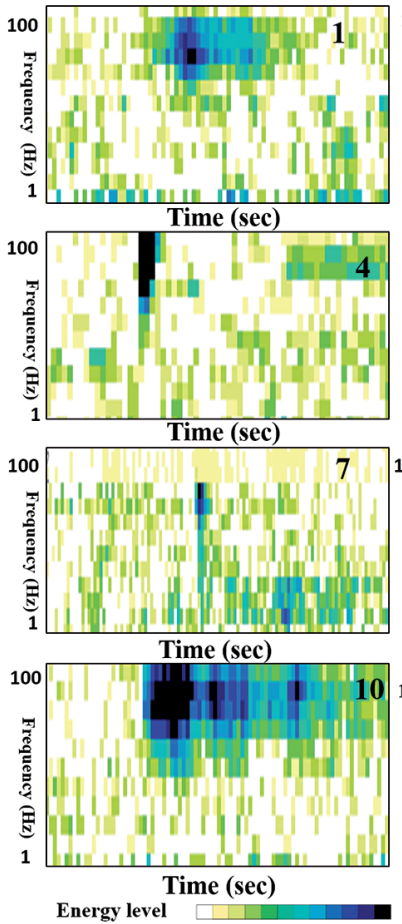
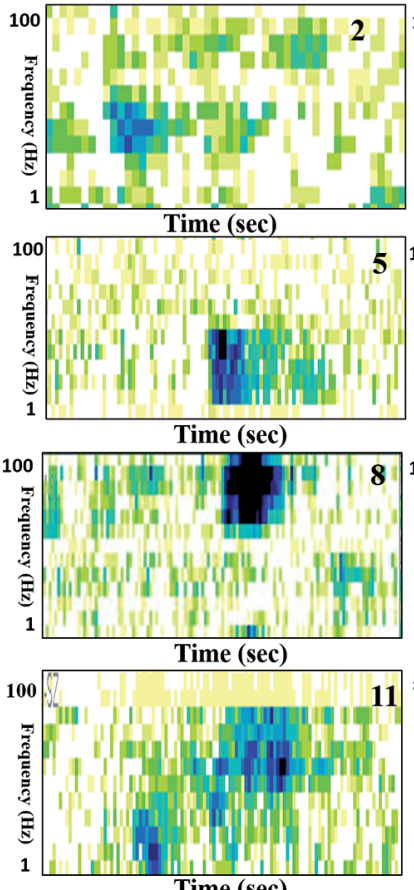

Time (sec)
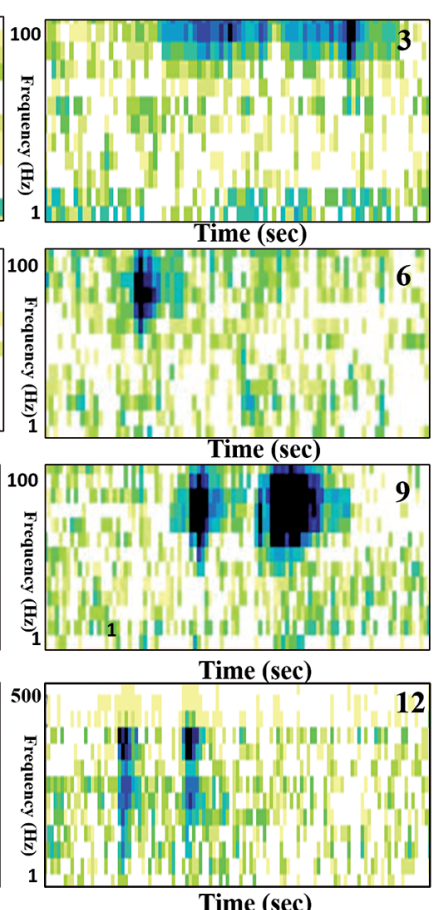

Figure 4

Extract of the supersonogram for after 3 hours of the pullout test, where at the end of experiment, the signals so identified were linked with the propagating shear zones in the tropical soil along the shear zones. The red box is zoomed sonogram images of the small energy shear event. The white rectangle contains the load-displacement curve of the EB pile pullout experiment recorded by four surrounding extensometers. The red arrow shows the time window where supersonogram is considered.

The sediment carrying energy of the river significantly increases during rainfall. The river can carry heavy sediments which can release high seismic energies which could be detected by the nearby seismometer. The energies are released by the abrasion of sediments with the bottom of the river reported by Burtin et al. (2010). In order to prove this, more controlled future experiments based on geotechnical and geodetic monitoring approaches are recommended. In this way, such signals can be linked with some clear source mechanisms.

Figure 5

Typologies of the signals observed the during rainy days (from 1 to 11) at Sobradinho landslide and from the pullout tests (12); only vertical component supersonograms are considered. 
There are two possible source mechanisms observed over the seismic records of the landslide. First, different signal typologies are observed during the rainy seasons (Figure 5) which can possibly be linked with the dynamism inside the landslide. The upper fine material of the landslide after rainfall, when converting back to initial dry state, releases energies through a mechanism referred to as a stress-relief

\section{Summary and conclusions}

The present study was carried out for characterization of the microseismic signals, due to propagating shear zone within the soil, generated by a pullout test on the expander body (EB) pile of tropical clayey soil. The detected signals were planned to be used as a benchmark for the seasonal dynamic analysis of the Sobradinho landslide that is representative of many landslides in the region, which developed in colluvial soil. At the Sobradinho landslide, the microseismic signals are naturally developed in the proximity of a sliding surface (colluvial-saprolite) in response to seasonal effects, such as an increase in pore-pressure combined with the dynamics created by the erosional effects of the Contagem River during and immediately after the rainfall events. No distinct phase onsets were identified on the seismic records of both experiments that made it difficult to localize the

\section{Acknowledgement}

The authors acknowledge the support of the following agencies: the National Council for Scientific and Technological Development (CNPq), mechanism. The associated microseismicity (observed in the testing) has been reported in previous studies (Walter et al., 2013; Fiorucci et al 2017).

There is lack of any supersonogrambased analogy among the signals released by EB pile test and landslide experiments. This is mainly because of at least three main reasons: a) different level of stress; b) different stress conditions (i.e. in a landslide mass the stress field is not necessarily compressive like in the pile penetration but also tensile, especially in the upper portion of the slope); c) a pre-existing sliding surface (in case of an already failed slope, like in the Sobradinho landslide case study) implies that residual strength is involved and not the peak ones. Therefore, rearrangement or crashing of soil particles should be assumed in residual strength conditions. event. Thus, event screening was performed through sonogram patterns. The following conclusions are drawn from the analysis.

1) The signal release in response to soil failure at the experiment of EB pile was of short duration and related positively with the increase in soil displacement, as observed on the load-displacement curve. It is possible to hypothesize that these signals are associated with propagating failure induced in the soil.

2) No nanoseismic signals (slidequakes) were detected on the Sobradinho landslide during the dry season, mainly because of the absence of dynamism in the landslide mass and low toe erosion, as well as the bedload carrying potential of the Contagem River.

3) In a saturated condition (rainy days), the typologies may be linked with the dynamic inside the landslide body.

the Support Research of the Federal District Foundation (FAP-DF), and the Pool of Brazilian Equipment (PegBr), Rio de Janeiro.
However, the propagative signals may be related to the river bedload after rain.

4) There was a lack of any supersonogram based analogy among the signals released by the EB pile test and landslide experiments.

Despite of its explorative nature, the study provides promising perspectives for future research on seismic emissions associated with landslide activities i.e. internal deformations and displacements. Further experimental investigations are required to monitor the variation in soil conditions by measuring the pore pressure and moisture content at multiple locations across the experimental sites - vertically and horizontally. The study might also benefit from further research in terms of element testing that investigates the effect of a saturation condition on the seismic behavior of the materials.

The first author would like to thank Mr. Dasiel H. Fernández for letting the seismic monitoring of his EB pile experiment.

\section{References}

ARCE, M., HERRERA, M. A. T. The Use of an expander body with full displacement piles in medium-dense sandy soils. In: GEO-CHINA INTERNATIONAL CONFERENCE, 4. Shandong, China, p. 142-151, 2016.

BRAGA, L.M., CALDEIRA, D., DA SILVA NUNES J. G., HUSSAIN Y., CARVAJAL, H. M., UAGODA, R. Caracterização geomorfológica e dinâmica erosivo-deposicional de encostas no vale fluvial do ribeirão Contagem-DF, Brasil. Anuário do Instituto de Geociências UFRJ, v. 41, n. 2, p. 51-65, 2018. (in Purtuguese).

BURTIN, A., VERGNE, J., RIVERA, L., DUBERNET, P. Location of river-induced seismic signal from noise correlation functions. Geophysical Journal International, v. 182, n. 3, p. 1161-1173, 2010.

FIORUCCI, M., IANNUCCI, R., LENTI, L., MARTINO, S., PACIELLO, A., PRESTININZI, A., RIVELLINO, S. Nanoseismic monitoring of gravity-induced slope instabilities for the risk management of an aqueduct infrastructure in Central Apennines (Italy). Natural Hazards, v. 86, n. 2, p. 345-362, 2017.

GOMBERG, J. P., BODIN, SAVAGE, W., JACKSON, E. Landslide faults and tectonic faults, analogs: the Slumgullion earthflow. Colorado. v. 23, n. 1, p. 41-44, 1995.

GOMBERG, J., SCHULZ, W., BODIN, P., KEAN, J. Seismic and geodetic signatures of fault

REM, Int. Eng. J., Ouro Preto, 72(3), 453-460, jul. sep. | 2019 
slip at the Slumgullion Landslide Natural Laboratory. Journal of Geophysical Research, 116, 2011.

HÄGE, M., JOSWIG, M. Spatiotemporal characterization of interswarm period seismicity in the focal area Nov' y Kostel (West Bohemia/Vogtland) by a short-term microseismic study. Geophysical Journal International, v. 179, n. 2, p. 1071-1079, 2009.

HAMZA O., BELLIS A. Gault Clay embankment slopes on the A14-Case studies of shallow and deep instability. In: ADVANCES IN TRANSPORTATION GEOTECHNICS; INTERNATIONAL CONFERENCE HELD IN NOTTINGHAM, UK. Proceedings... CRC Press. 2008. p. 307.

HUSSAIN, Y., MARTINEZ-CARVAJAL, H., CARDENAS-SOTO, M., MARTINO, S.A. Brief introduction to nanoseismic monitoring. In: INTERNATIONAL CONGRESS OF THE BRAZILIAN GEOPHYSICAL SOCIETY \& EXPOGEF, 15. Rio de Janeiro, Brazil, 2017, p. 636-640.

HUSSAIN, Y., MARTINEZ-CARVAJAL, H. CARDENAS-SOTO, M. MARTINO, S.A. Introductory review of potential applications of nanoseismic monitoring in seismic energy characterization. Journal of Engineering Research, v. 7, n. 2, p. 65-80, 2019.

JOSWIG, M. Pattern recognization for earthquake detection. Bulletin of the Seismological Society of America, v. 80, n. 1, p. 170-186, 1990.

JOSWIG, M. Nanoseismic monitoring fills the gap between microseismic networks and passive seismic. First Break, v. 26, n.6, p. 117-124, 2008.

MARTINS T. D., VIEIRA B. C., FERNANDES N. F., OKA-FIORI C., MONTGOMERY D. R. Application of the SHALSTAB model for the identification of areas susceptible to landslides: Brazilian case studies. Revista de Geomorfologie, v. 19, p. 136-144, 2017.

PLANÈ, T., MOONEY, M. A., RITTGERS, J. B. R., PAREKH, M. L., BEHM, M., SNIEDER, R. Time-lapse monitoring of internal erosion in earthen dams and levees using ambient seismic noise. Geotechnique, v. 66, n. 4, p. 301-312, 2015.

PROVOST, F., HIBERT, C., MALET, J. P. Automatic classification of endogenous landslide seismicity using the Random Forest supervised classifier. Geophysical Research Letters, v. 44, p. 113-120, 2017

SICK, B., WALTER, M., JOSWIG, M. Visual event screening of continuous seismic data by supersonograms. Pure and Applied Geophysics, v. 171, n. 3-5, p. 549-559, 2014.

SILVA, M.T.M.G. Metodologia para determinação de parâmetros para solos não saturados utilizando ensaios com umidade conhecida. Brasília: MSc. Universidade de Brasília, 2009. (Msc. Dissertation).

TONNELliER, A., HELMSTETTER, A., MALET, J. P., SCHMITTBUHL, J., CORSINI, A., JOSWIG, M. Seismic monitoring of soft-rock landslides: the Super-Sauze and Valoria case studies. Geophysical Journal International, v. 193, n. 3, p. 1515-1536, 2013.

VOUILLAMOZ, N., ROTHMUND, S., JOSWIG, M. Characterizing the complexity of microseismic signals at slow-moving clay-rich debris slides: the Super-Sauze (southeastern France) and Pechgrabe (Upper Austria) case studies. Earth Surface Dynamics, v. 6, n. 2, 2018.

WALTER, M., WALSER, M., JOSWIG, M. Mapping rainfall-triggered slidequakes and seismic landslide-volume estimation at Heumoes slope. Vadose Zone Journal, v. 10, n. 2, p. 487-495, 2011.

WALTER, M., ARNHARDT, C., JOSWIG, M. Seismic monitoring of rockfalls, slide quakes, and fissure development at the Super-Sauze mudslide, French Alps. Engineering Geology, v. 128, p. 12-22, 2012.

WALTER, M., GOMBERG, J., SCHULZ, W., BODIN, P., JOSWIG, M. Slidequake generation versus viscous creep at softrock-landslides: synopsis of three different scenarios at slumgullion landslide, heumoes slope, and super-sauze mudslideslidequake generation vs. viscous creep at softrock-landslides. Journal of Environmental and Engineering Geophysics, v. 18, n. 4, p. 269-280, 2013.

WALTER, M., JOSWIG, M. Seismic characterization of slope dynamics caused by softrock-landslides: The Super-Sauze case study. In: INTERNATIONAL CONFERENCE ON LANDSLIDE PROCESSES: FROM GEOMORPHOLOGIC MAPPING TO DYNAMIC MODELLING, p. 215-220, 2009.

Received: 7 August 2018 - Accepted: 10 April 2019.

(c) BY All content of the journal, except where identified, is licensed under a Creative Commons attribution-type BY. 